\title{
Dentists Knowledge and Attitude about Confidentiality and Privacy of the Patients in Saudi Arabia
}

\author{
Alya Fahad Alkhalifah ${ }^{a}$ Sarah Muhammad Alsadiq $^{\mathrm{b}}$ Omnia Ata Elsid ${ }^{\mathrm{c}}$ \\ Belal Mohamad Alsadiq ${ }^{d}$ Poonam Agarwal ${ }^{\mathrm{e}}$ \\ ${ }^{a}$ General Dentist at Saudi MOH, Qassim, Kingdom of Saudi Arabia; ${ }^{b}$ General Dentist, Madina, Kingdom of Saudi \\ Arabia; 'Dental Intern at Buraydah Private Colleges, Buraydah, Saudi Arabia; ${ }^{\mathrm{d}} 6 \mathrm{th}$ Year Dental Student at Buraydah \\ Private Colleges, Buraydah, Saudi Arabia; ${ }^{e} B D S$, MDS Oral Medicine, Diagnosis \& Radiology, Dentistry Department, \\ Assistant Professor at Buraydah Private Colleges, Buraydah, Saudi Arabia
}

\section{Keywords \\ Confidentiality · Privacy · Dentist · Knowledge · Attitude}

\begin{abstract}
Background: Privacy and confidentiality are critical elements of patient care. Dentists are ethically obliged to protect patient confidentiality and ensure discretion. Confidentiality is significant to patients' well-being and establishes confidence in relationships between the doctor and patient. The aim of our study was to determine the level of knowledge about patient confidentiality, actuate the proper attitude when breaching patient confidentiality, and highlight the importance of consent forms for each patient's release of confidential information. Methods: A cross-sectional study was conducted with 411 dentists in Saudi Arabia, using an anonymous self-administrated questionnaire that consisted of three parts: sociodemographic data, knowledge, and the third part was the attitude. Data were analyzed by descriptive and analytical statistics using SPSS. $\boldsymbol{R e}$ sults: Results show a significant relationship between knowledge and age ( $r=0.470, p<0.05)$, qualification $(r=0.453$, $p<0.06)$, and experience ( $r=0.430, p<0.05)$, whereas a less significant relationship occurred between gender and
\end{abstract}

karger@karger.com www.karger.com/sjh

Karger!

GOPEN ACCESS
C 2022 The Author(s).

Published by S. Karger AG, Basel

This is an Open Access article licensed under the Creative Commons Attribution-NonCommercial-4.0 International License (CC BY-NC) (http://www.karger.com/Services/OpenAccessLicense), applicable to the online version of the article only. Usage and distribution for commercial purposes requires written permission. knowledge $(r=-0.177, p<0.05)$. There were also significant relationships between qualification and attitudes in terms of commenting on a patient to colleagues $(r=-0.138, p<0.05)$, friends, or general discussion of confidential information in the waiting room $(r=-0.210,<0.05, r=-0.161, p<0.05)$; however, these aforementioned correlations were conflicted among the answers of the respondents. Conclusion: Dental programs should address issues concerning confidentiality in order to increase sensitivity of healthcare professionals toward respecting confidentiality of each and every patient.

(c) 2022 The Author(s)

Published by S. Karger AG, Basel

\section{Introduction}

Medical and dental professionals have an obligation to their patients to follow the guidelines of the medical and dental professional codes in their respective societies and cultures $[1,2]$. Notably, the confidentiality and privacy of patient data are critical aspects of the physician-patient relationship and core ethical standards in medicine [3]. Respect for the principles of beneficence, nonmaleficence, and autonomy is acknowledged as forming the ba- 
sis of patient confidentiality from an ethical point of view based on a fundamental consideration for humans [4].

In the medical field, confidentiality refers to "the principle of keeping secure and secret from others, information given by or about an individual in the course of a professional relationship" [5]. Such information is considered confidential, inferring that those who possess the information have a responsibility to protect it from others who are not entitled to this information. Furthermore, confidentiality is the right of an individual to have their personal, identifiable medical information kept private and can be defined as the promise or duty to protect private information $[6,7]$.

Dentists obtain sensitive personal information from their patients in order to understand their medical problems. Such personal information is considered confidential. Patients grant healthcare practitioners access to their bodies for medical examinations and treatment, but they also expect these professionals to protect them from any unnecessary physical or emotional harm. As such, those who possess patients' information have a responsibility to protect it from others who are not entitled to this information.

According to the Saudi Arabian Ministry of Health $(\mathrm{MOH})$, it is illegal to use and/or disclose patient information, including medical records and private and personal information, unless the patient has given their permission to do so, or disclosure is required by a court. It is also forbidden to meet with and disclose personal information to anyone who does or does not have a relationship with the patient, including visitors, friends, and family members who are not accountable for the patient's care. Accordingly, the stringent regulation of obtaining the patient and caregiver's identification cards prior to any treatment is critical [8].

Contending with ethical dilemmas in clinical practice is a daily occurrence in almost all health institutions worldwide $[9,10]$. These situations may result in unpleasant conflicts between dentists and their patients, which may occasionally result in litigation. This issue raises the question of whether dentists know how to apply patients' rights with respect to privacy and confidentiality in their everyday practice. In a brief comment about this issue in 1982, Siegler[11] stated that anything patients may be concerned about can be considered confidential information. However, more common problems relating to confidentiality are faced in everyday practice among dentists who unintentionally disclose information about a particular patient. For example, two doctors may discuss a patient during their lunch break in the hospital cafeteria. These healthcare providers may be oblivious to the pos- sibility that the patient's visitors could be sitting in the same cafeteria and be able to hear their discussion. The conversation may be loud enough for the visitors to hear every word [9]. Another example is when doctors talk about a patient in public, such as in the hallway of a hospital, which may allow other families to hear what the doctors are saying. We therefore conducted a study to assess the knowledge and attitudes of dentists toward patient privacy and confidentiality. The aim of this study was to determine dentists' levels of knowledge about patient confidentiality, to actuate appropriate attitudes when breaching patient confidentiality, and to highlight the importance of patient consent forms when dealing with confidential information.

\section{Materials and Methods}

\section{Study Design and Setting}

This cross-sectional study was conducted with dentists from Saudi Arabia for a period of 5 months from January to March 2020. To ensure clarity and to assess its validity, the questionnaire was initially administered to 15 participants who were not involved in the study. The pilot study was conducted with dental professionals, and the collected data were subsequently analyzed. The results of the pilot study were found to match the study objectives, and suitable modifications were performed before field administration. According to the Saudi statistical yearbook, there were 16,752 dentists living in Saudi Arabia in 2018 [12]. Using a sample size calculator with an acceptable margin of error equal to $5 \%$ and the effect of designing two with a confidence interval of $95 \%$, a sample comprising at least 376 respondents was required. The total number of respondents included in the final analysis was 411 .

\section{Data Collection Tools}

An anonymous self-administrated questionnaire was developed in English and Arabic for this study. No personal information such as first names, surnames, dates of birth, and addresses was registered. The questionnaire consisted of three parts. The first section included questions regarding the respondents' sociodemographic data (i.e., gender, age, qualifications, and work experience); the second comprised questions regarding dentists' knowledge of confidentiality; and the third assessed the attitudes of the dentists toward confidentiality. A five-point Likert scale with responses ranging from "never" to "always" was used. The survey was created on the Google Forms platform. The link was posted on Twitter and sent by email to a list of dentists in Saudi Arabia. The data collection process was conducted over 3 months from January to March 2020.

\section{Data Collection Methods}

The data were collected via an online survey. The link was distributed to dentists in Saudi Arabia using a nonrandom sampling technique. The initial respondents were thus approached using their social networks or via referrals. The objectives of this study were explained to the potential respondents, who subsequently provided informed consent in Arabic or English before completing 
Fig. 1. Gender/age and the distribution response of the demographic data shows the overall demographics of the study sample. The majority of respondents were male, i.e., $63 \%(n=259)$. The age was divided into four groups, the majority being in the age range of $20-30$ years $(38.2 \%)(n=157)$, while only $14.6 \%(n=60)$ were above 45 years of age.

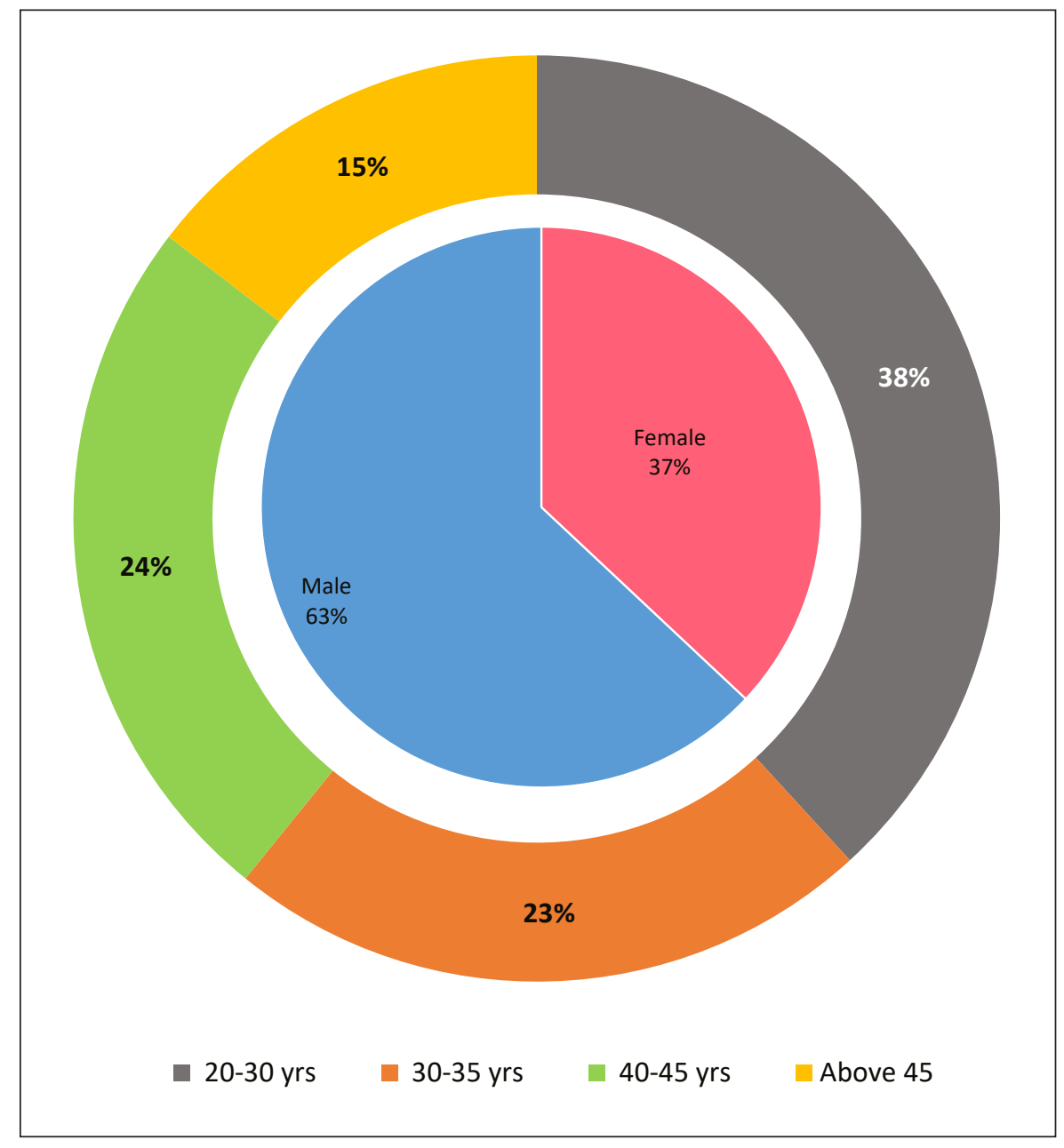

the questionnaire. Ethical approval for this study was obtained from the $\mathrm{MOH}$, regional research Ethical Committee (no. 14411618727).

\section{Data Analysis}

Descriptive and inferential statistical tests were used to analyze the data in this study. Means, standard deviations, and standard of errors were used as the descriptive statistics. For the inferential statistics, correlations were used to meet the specific objectives. The level of significance was set at 0.05 , and all the hypothesis testing used a two-sided hypothesis. In addition, we utilized the statistical program Statistical Package for the Social Sciences (IBM SPSS version 25).

\section{Results}

A total of 411 responses were received. Figures 1 and 2 show the distribution of the responses according to the respondents' demographic data. Most of the respondents $(63 \%, n=259)$ were male. Among the respondents, $38.2 \%$
( $n=157)$ were aged $20-30$ years, while only $14.6 \%(n=$ 60) were 45 years or older. Most of the respondents $(30.9 \%, n=172)$ were dental interns, whereas a few $(17.8 \%, n=73)$ were specialists. In terms of years of experience, approximately $42 \%(n=172)$ had less than 5 years of experience, and only $18.2 \%(n=75)$ had more than 10 years of clinical dental experience.

Table 1 shows the distribution of the respondents' knowledge. With respect to the first question, $83 \%$ of the respondents understood that patients have a right to confidentiality. For question 2, 75\% agreed that patients are entitled to privacy and confidentiality, while two-thirds (67\%) of the respondents acknowledged that written consent was necessary for each patient (question 3). Furthermore, $63 \%$ of the respondents believed that patients were entitled to determine who could and could not be told about their medical conditions (question 4). Meanwhile, $66 \%$ were fully aware of the circumstances in which they were permitted to violate patients' confidentiality regard- 


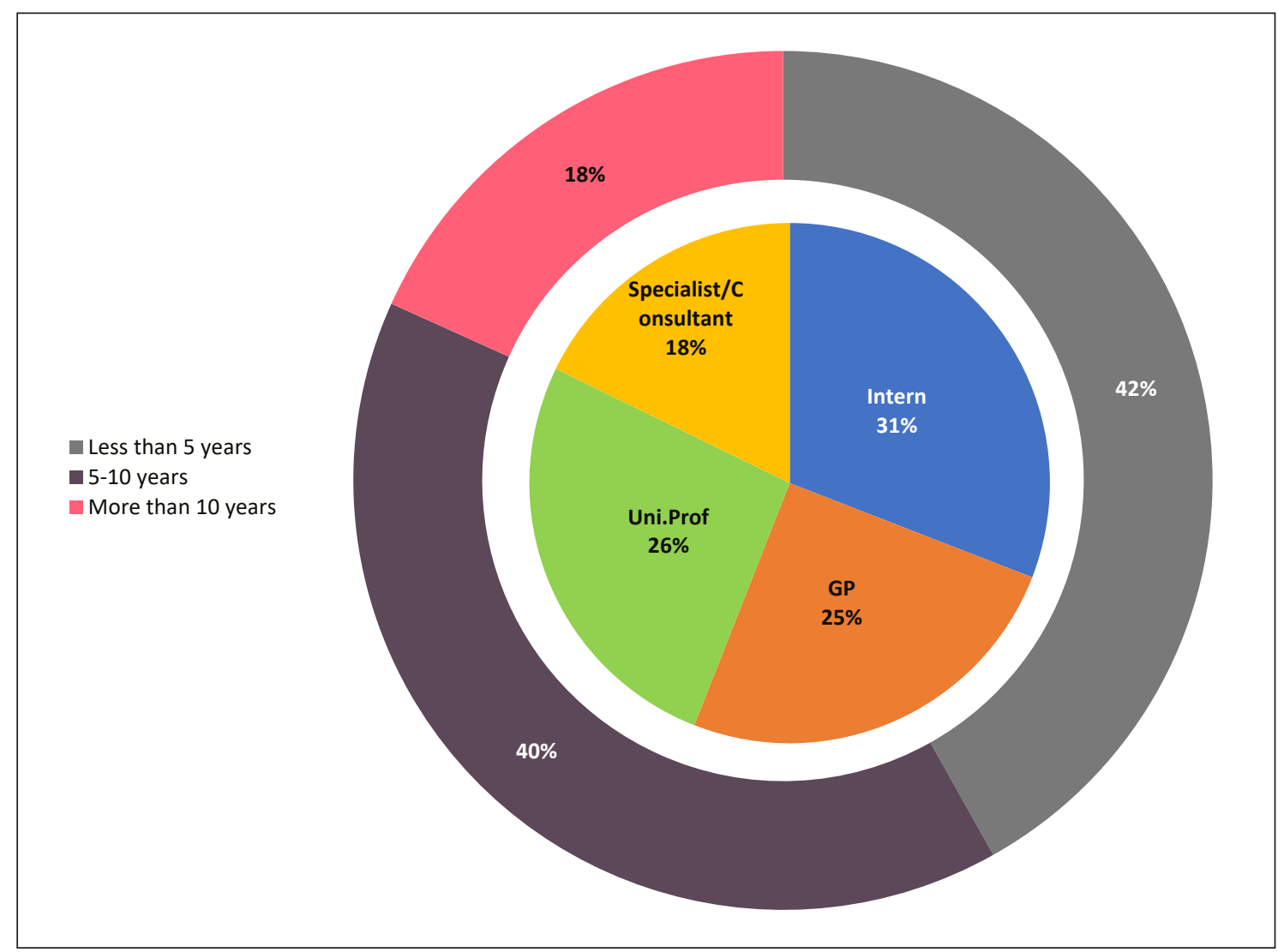

Fig. 2. Qualification/years of experience and the distribution response of the demographic data. The figure shows most respondents were dental interns $30.9 \%(n=172)$, whereas the minority were specialists $(n=73) 17.8 \%$. In terms of years of experience, approximately $42 \%(n=172)$ had less than 5 years, while only $18.2 \%(n=75)$ had more than 10 years of clinical dental experience.

ing their medical conditions (question 5). Nonetheless, $33.6 \%$ were unaware of such circumstances. Just over half (51\%) of the respondents knew to whom they had a legal obligation to disclose dental records (i.e., the $\mathrm{MOH}$ and government authorities, which is in accordance with special regulations, patient insurance companies, and judicial authorities; question 6). However, 56\% misunderstood their obligation to warn staff members to keep patient information confidential (question 7). Most of these respondents (68\%) were dental interns, while $60.2 \%$ were university professors, and $56.3 \%$ were general practitioners. When asked about granting patients access to their medical reports (question 8 ), 55\% responded that patients should have access to their medical reports. Among them, $93.5 \%$ were specialists, and $68.5 \%$ were university professors. However, $45.5 \%$ of the respondents disagreed. They included mostly dental interns (68.5\%), followed by practitioners in general practice (59.2\%). In their answers to the last question (question 8 ), 53\% of the respondents believed that they were permitted to store patients' confidential details on their personal devices. Of the respondents who answered the opposite, $24.7 \%$ were specialists, $47.2 \%$ were dental interns, $50 \%$ were university professors, and $58.3 \%$ were general practitioners.

The relationship between the respondents' sociodemographic data and knowledge was evaluated (Table 2). The results showed a significant positive relationship between knowledge and age $(r=0.470, p<0.05)$, qualifications $(r=0.453, p<0.06)$, and experience $(r=0.430, p<$ $0.05)$. On the other hand, there was a significant negative relationship between gender and knowledge $(r=-0.177$, $p<0.05)$.

Descriptive statistics were used to explain dentists' attitudes toward patient confidentiality and privacy (Table 3). Additionally, the analysis of the relationship between dentists' attitudes and sociodemographics (Table 4) indicated that there was a negative relationship between sociodemographic dentists' attitudes. Hence, 
Table 1. The distribution of knowledge among the respondents of the study sample $(n=411)$

\begin{tabular}{|c|c|c|c|c|c|c|}
\hline \multirow[t]{2}{*}{ Questions } & & \multicolumn{4}{|c|}{ Qualifications } & \multirow{2}{*}{$\begin{array}{l}\text { Total \% within } \\
\text { qualification } \\
(n=411)\end{array}$} \\
\hline & & $\begin{array}{l}\text { dental } \\
\text { interns } \\
(n=127)\end{array}$ & $\begin{array}{l}\text { general } \\
\text { practice } \\
(n=103)\end{array}$ & $\begin{array}{l}\text { university } \\
\text { professor } \\
(n=108)\end{array}$ & $\begin{array}{l}\text { specialist/ } \\
\text { consultant } \\
(n=73)\end{array}$ & \\
\hline \multirow{2}{*}{$\begin{array}{l}\text { Patients confidentiality is keeping the information of } \\
\text { the patient in private }\end{array}$} & Correctly, \% & 81.9 & 79.6 & 83.3 & 91.8 & 83.5 \\
\hline & Incorrectly, \% & 18.1 & 20.4 & 16.7 & 8.2 & 16.5 \\
\hline \multirow[t]{2}{*}{ Does the patient have the right to confidentiality } & Correctly, \% & 63.0 & 75.7 & 78.8 & 89.0 & 74.9 \\
\hline & Incorrectly, \% & 37.0 & 24.3 & 21.2 & 11.0 & 25.1 \\
\hline \multirow[t]{2}{*}{ Is written consent necessary for every patient } & Correctly, \% & 55.9 & 73.8 & 65.7 & 76.7 & 66.7 \\
\hline & Incorrectly, \% & 44.1 & 26.2 & 34.3 & 23.3 & 33.3 \\
\hline \multirow{2}{*}{$\begin{array}{l}\text { Does the patient have a right to decide who may be } \\
\text { informed or forbidden to know about their medical } \\
\text { condition }\end{array}$} & Correctly, \% & 47.2 & 64.1 & 66.7 & 83.6 & 63.0 \\
\hline & Incorrectly, \% & 52.8 & 35.9 & 33.3 & 16.4 & 37 \\
\hline \multirow{2}{*}{$\begin{array}{l}\text { Under which circumstance are you allowed to breach } \\
\text { the confidential information of the patient }\end{array}$} & Correctly, \% & 47.2 & 61.2 & 78.7 & 89.0 & 66.4 \\
\hline & Incorrectly, \% & 52.8 & 38.8 & 21.3 & 11.0 & 33.6 \\
\hline \multirow{2}{*}{$\begin{array}{l}\text { Whom do you have an obligation of revealing dental } \\
\text { records }\end{array}$} & Correctly, \% & 37.0 & 35.9 & 63.9 & 79.5 & 51.3 \\
\hline & Incorrectly, \% & 63.0 & 64.1 & 36.1 & 20.5 & 48.7 \\
\hline \multirow{2}{*}{$\begin{array}{l}\text { As a dentist, do you have the duty to warn everyone } \\
\text { who possesses confidential information to keep it } \\
\text { secret }\end{array}$} & Correctly, \% & 31.5 & 43.7 & 39.8 & 69.9 & 43.6 \\
\hline & Incorrectly, \% & 68.5 & 56.3 & 60.2 & 30.1 & 56.4 \\
\hline \multirow{2}{*}{$\begin{array}{l}\text { Does the patient have accessibility to their medical } \\
\text { reports }\end{array}$} & Correctly, \% & 31.5 & 40.8 & 68.5 & 93.2 & 54.5 \\
\hline & Incorrectly \% & 68.5 & 59.2 & 31.5 & 6.8 & 45.5 \\
\hline \multirow{2}{*}{$\begin{array}{l}\text { Are you allowed to keep the confidential information } \\
\text { of your patients in your own personal devices }\end{array}$} & Correctly \% & 47.2 & 58.3 & 50.0 & 24.7 & 46.7 \\
\hline & Incorrectly, \% & 52.8 & 41.7 & 50.0 & 75.3 & 53.3 \\
\hline \multicolumn{2}{|l|}{ The total percentage of knowledge, $\%$} & 49.16 & 59.23 & 66.16 & 77.49 & 61.17 \\
\hline
\end{tabular}

Table 2. Correlations among age, qualification, work experience, and knowledge $(n=411)$

\begin{tabular}{|c|c|c|c|c|}
\hline Age & $-0.202^{*}$ & 1 & $0.900^{*}$ & $0.847^{*}$ \\
\hline Qualification & $-0.143^{*}$ & $0.900^{*}$ & 1 & $0.814^{*}$ \\
\hline Experience & $-0.151^{*}$ & $0.847^{*}$ & $0.814^{*}$ & 1 \\
\hline Under which circumstance are you allowed to breach the confidential information of the patient & $-0.213^{*}$ & $0.352^{*}$ & $0.334^{*}$ & $0.289 *$ \\
\hline Whom do you have an obligation of revealing dental records & -0.091 & $0.322^{*}$ & $0.325^{*}$ & $0.249^{*}$ \\
\hline Does the patient have accessibility to their medical reports & $-0.148^{*}$ & $0.395^{*}$ & $0.386^{*}$ & $0.325^{*}$ \\
\hline
\end{tabular}

$* p<0.05$ 
Table 3. Descriptive statistics for the attitudinal responses $(n=411)$

\begin{tabular}{|c|c|c|c|c|}
\hline Disclose the patient confidential information to their family member & 2.38 & 1.368 & 2.00 & 3 \\
\hline Commenting on a patient to a friend & 1.01 & 0.995 & 1 & 2 \\
\hline Commenting on a patient to colleagues & 2.23 & 1.380 & 2.00 & 3 \\
\hline Can confidential information be discussed in waiting rooms & 1.10 & 1.00 & 0.985 & 2 \\
\hline Patients records should always be adequately stored & 3.25 & 0.959 & 4.00 & 2 \\
\hline Can an unauthorized member have the accessibility of the confidential records & 0.68 & 0.855 & 0.00 & 1 \\
\hline
\end{tabular}

Scale: 0 , never; 1 , almost never; 2 , sometimes; 3 , often; and 4, almost always.

other factors may have also affected the dentists' attitude and further studies are needed to ascertain the same. However, concerning the relationship between qualification and commenting on a patient either to colleagues $(r$ $=-0.138, p<0.05)$, friends, or discussing the patient confidential information in the waiting room $(r=-0.210$, $<0.05, r=-0.161, p<0.05)$, these aforementioned correlations were negative among the answers of the respondents.

\section{Discussion}

Confidentiality is an important and necessary aspect of professional medical practice. The foundations of professional confidentiality go back to Hippocrates[13] in 1849 , who stated, "Whatever, in connection with my professional practice, or not in connection with it, I see or hear, in the life of men, which ought not to be spoken of abroad, I will not divulge, as reckoning that all such should be kept secret." Since then, professional confidentiality and privacy have been both legal and ethical requirements for all healthcare providers. The present study provides insight into the value dental practitioners in Saudi Arabia place on patient confidentiality. Dentists must be aware of the legal and ethical obligations they have to patients to provide a protective and private treatment setting so that patients may pursue the care they need unhindered by fears of exposure $[14,15]$.

We examined the perspectives of dentists regarding professional privacy and confidentiality in the first part of our questionnaire. Without knowledge of confidentiality, dentists can neither protect the rights of their patients nor exercise their obligations regarding confidentiality completely.

Knowledge and Attitude about Confidentiality
The first two questions in our survey examined the dentists' knowledge about the meaning of confidentiality, which is a legal obligation. A lack of such knowledge can lead to ethical issues. In the UK, the General Dental Council's Principles of Patient Confidentiality indicate that dentists are responsible for keeping patient information confidential, with concessions only for specific given purposes [10].

According to the Canadian medical associations' policy principle for the protection of patient privacy, the duty to maintain patient confidentiality, like trust, is fundamental to the therapeutic nature of the patient-physician relationship; it creates conditions that allow patients to openly and confidently share their complete health information, resulting in a stronger physician-patient relationship and the delivery of better care. The Saudi guidelines regarding medical ethics mandate the need for medical professionals to obtain informed consent, maintain confidentiality, not disclose patient information, and not violate patient privacy [16].

In the third question in our study, the respondents were asked whether it is necessary to obtain written consent from each patient. Using confidential data for purposes other than the delivery of healthcare (e.g., teaching/ lecturing and research) requires unambiguous written consent from the patient, and this should be registered by the clinician [10]. Seeking patients' permission to reveal information is necessary irrespective of whether patients could be identified from the disclosure. Patients must also be provided with clear details about the potential for a breach of confidentiality where ICD-10 coding is used [17]. According to the Saudi Guidelines for Informed Consent, clinicians must further make sure that the medical procedure matches the information for which the patient signed their informed consent [16]. 
The respondents in our study were asked whether a patient is able to choose to whom their confidential data are disclosed. Most of the respondents stated that it is the patient's right to choose. Some dentists however did not feel that patients have this right. This was possibly deemed likely in the case of immature patients who need to be cared for and guarded. According to the Saudi $\mathrm{MOH}$, privacy and confidentiality must be maintained when discussing a patient's treatment program, whether with the patient or their legal guardian [8].

Questions 5 and 6 in our study addressed the issue of the obligatory disclosure of dental records and the circumstances under which the sharing of confidential information is allowed. According to Saudi $\mathrm{MOH}$, it is necessary to prevent the diversion, abuse, dissemination, or access to patient information (e.g., medical files and medical details relevant to a diagnosis) without the consent of the patient or their legal guardian (except as required by the judiciary). Additionally, it is crucial to prohibit access to patients' medical records by nonmedical staff members who supervise treatment or are approved by the hospital, patient, judicial authorities, or guardian [8]. Disclosing patient information is permitted in the following circumstances: when referring the patient to another dentist/ physician, when informing the patient's family that has been approved by the patient, and when the confidential information may threaten the lives and/or health of others. The $\mathrm{MOH}$ and related government authorities, judicial authorities, and patients' insurance companies are the parties to whom there is an obligation to reveal dental records. In Croatia, in accordance with special regulations, these parties include the Ministry of Health and State Administration, the Croatian Chamber of Dental Medicine, and judicial authorities [14]. Thus, doctors should not hesitate to seek legal counsel when in doubt of the legal basis for sharing sensitive information with another person or entity.

In a similar study of dentists in Croatia, only $11.4 \%$ of the respondents stated that they had a responsibility to advise patients that confidential information would be kept private and that they did not have to remind them of this on a regular basis [14]. In contrast, $43.6 \%$ of the respondents in our study indicated that they understood that part of their duty is to advise patients that their confidential information would be kept secret. According to the Saudi $\mathrm{MOH}$, the following disciplinary penalties can be administered by the institutional Ethics Committee if a healthcare practitioner discloses a patient's information to others without legal justification: (1) a warning; (2) a monetary penalty of not more than 10,000 riyals; and (3)

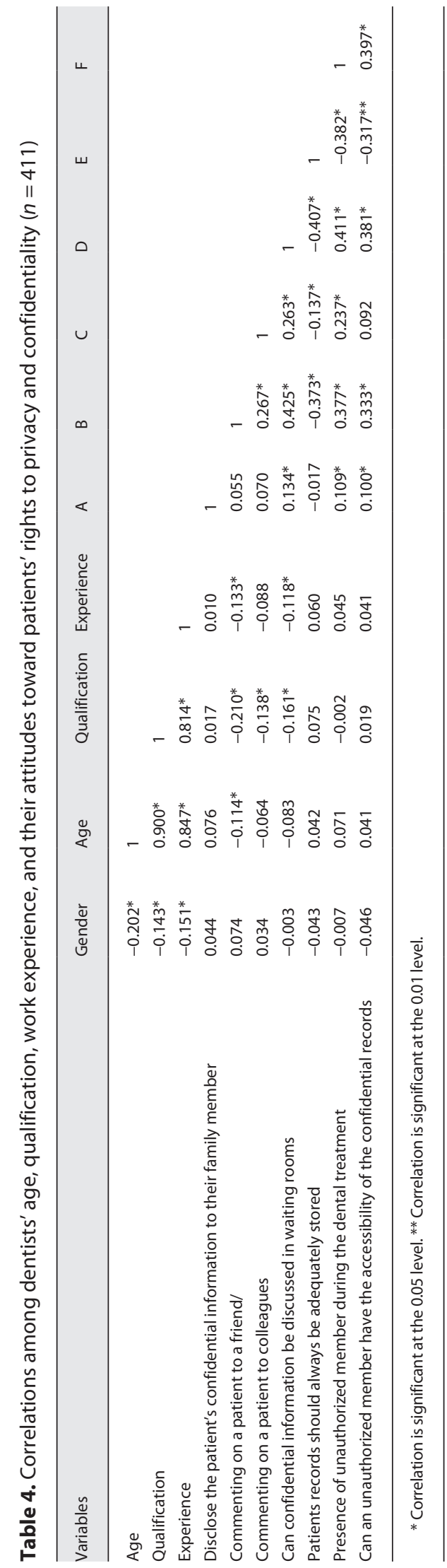

Alkhalifah/Alsadiq/Elsid/Alsadiq/Agarwal 
cancellation of the practitioner's license to practice in the health profession and the removal of their name from the register of licensees [17]. To maintain confidentiality, dentists should therefore warn their employees and all individuals collecting patient information of this obligation.

Under the Saudi Data Protection Act (1998), patients have the right to access their medical and dental records and/or obtain copies thereof [2]. Additionally, the $\mathrm{MOH}$ has stated that patients have the right to obtain a copy of their medical reports to facilitate their follow-up with a local doctor and/or hospital, where appropriate, and to seek the opinion of another healthcare professional without compromising their continuity of care [8].

The eighth question in our study concerned a patient's right to access their own records, as well as where to refer them to if their records are needed. More than half (54.5\%) the respondents indicated that patients have the right to access and/or obtain copies of their medical and dental records. In a study among the National Health Service clinical members of staff in the Orthodontic Department at Eastman Dental Hospital in the UK, 89\% of the respondents provided the same answer [10], which demonstrates a higher level of knowledge in that hospital than among the respondents in our study.

In response to question 9 in our survey, half the respondents were aware that patients' confidential information cannot be kept on a doctor's personal electronic device. A dentist must ensure that any sensitive information about patients is adequately secured against unauthorized access, disclosure, or loss. Records should not be left unattended, either on a paper or on a computer. The exchange of passwords should be avoided, and photographs or videos taken as part of the patient's clinical care should be downloaded as soon as possible to a secure computer, and the images on the camera deleted. Dentists using their personal computers or laptops to store patient information are considered to be in breach of patient confidentiality [17]. Portable computers, medical notes, and information should not be left in unattended cars or easily accessible places. When not in use, all files and portable devices must be locked away and kept out of sight. Staff should not take patient records home; however, where this cannot be avoided, procedures for safeguarding the information effectively should be agreed locally [3]. Contrarily, conceder violated the patient confidentiality.

Among the dentists in this study, older age, more years of experience, and higher qualifications improved the level of knowledge of patient confidentiality and privacy.
Additionally, age, qualifications, and experience were positively correlated and statistically significant with respect to the conditions under which dentists are permitted to disclose patients' confidential details, who is permitted to review dental records, and how patients can access their medical reports. Gender was however negatively associated with knowledge of the situations in which dentists are permitted to violate patient confidentiality and provide access to patients' medical reports. Notwithstanding, the gender of the dentists was not statistically significant in terms of having an understanding of the obligation to disclose dental records.

In the second part of our study, we queried the attitudes of the dentists toward patients' rights to privacy and confidentiality. Most patients prefer to have their medical information remain confidential. According to the $\mathrm{MOH}$ of Saudi Arabia, patients have the complete right to know their diagnosis, and no other member of their family has the right to know their confidential information except with the permission and approval of the patient themselves [8]. Nonetheless, when questioned about these obligations, many of the dentists' attitudes toward revealing confidential patient information was unfortunately opposed to the guidelines [8], even though most of the respondents were aware that it is indeed a violation of confidentiality to comment on any patient's healthcare status to their friends, family members, or even a colleague who does not have any relation to the patient.

Dentists are forbidden from revealing any confidential patient information to any individual or discussing patients with anyone without first asking for specific permission. An exception to this rule is if another dentist is also involved in the treatment of the same patient or if the discussion is required for a second opinion/consultation [6]. Our findings were similar to those of the study of dentists from the Croatian Chamber of Dental Medicine, who had no reservation in sharing patient information with other dentists [14]. This is legal in Croatia if the patient has been referred for a consultation. Even if consent is not provided by the patient to release their medical information to another dentist, it is simply part of the work protocol. In Saudi Arabia, computerized systems with sufficient security to control access to only responsible users who comply with the Data Protection Act and the Caldicott Principles should be used [10].

Patients' medical records should be kept secure at all times and only checked by an authorized individual when they need to use them for an authorized purpose. Medical records should never be left in a location where unauthorized individuals can access them. The disclosure of con- 
fidential information may cause intrinsic harm if it becomes known to others as this may negatively affect the patient's reputation or cause economic harm [17]. Patients could lose their job, health insurance, or even housing. In some cases, disclosure of the wrong type of information to the public may lead to threats to the life of the patient. Patients could also experience social or psychological harm. For example, disclosing that a patient may be infected with the hepatitis B virus or another type of transmitted disease can cause social isolation and/or other psychologically harmful outcomes, especially if the actual results confirm rumors. In such cases, the patients will likely never be able to trust their doctors or dentists and may hide important information that could benefit their treatment [17]. Doctors, dentists, and their staff must store medical and dental records securely before leaving the office so that they cannot be accessed by any other staff members or unauthorized individuals [14]. The results of our study regarding dentists' attitudes toward patient records and access to confidential information by unauthorized individuals support the findings of previous studies, which established the belief among dentists that it is part of a dentist's duty to keep confidential information a secret and to ensure that patients' confidential information is kept private and stored in a safe place $[14,17]$.

It is mandatory for dentists to remind their coworkers or whoever is present in the dental clinic during a procedure that they should keep patient information confidential. It is important for dentists to know their responsibilities and understand their ethical and legal duties and their consequences. Thus, it is a dentist's duty to respect the privacy and confidentiality of patients. Enabling patients to decide how their information is disclosed is an important element of healthcare and helps keep patients engaged as active partners in their treatment.

\section{Conclusion}

Privacy and confidentiality are regarded primarily as a means to an end. They protect the health of the population by allowing individuals to access medical care and treatment without a fear of embarrassment or other harm. Privacy and confidentiality are both legal and ethical obligations and make up the core features of the physicianpatient relationship. It is further commonly known that decorum prevents people from disclosing people's private matters to others.
From the findings of our study, we can infer that knowledge and good attitudes toward patient confidentiality are positively moderated by dentists. Their duties and the rights of patients should therefore be better known. Dental programs should address the issues of confidentiality and privacy in order to make healthcare professionals more sensitive toward the needs of patients and to respect the confidentiality of each and every patient.

\section{Statement of Ethics}

The completion of the questionnaire is taken as consent to participate in the study. The ethical approval for this study was obtained from Saudi MOH, regional research Ethics Committee, Qa$\operatorname{ssim}(1441-1618727)$.

\section{Conflict of Interest Statement}

The authors have no conflicts of interest to declare.

\section{Funding Sources}

The authors received no specific funding for this work.

\section{Author Contributions}

Sara Alsadiq and Alya Alkhalifah conceived the presented idea, developed the theory, and performed the computations. Omnia Ata Elsid and Belal Alsadiq analyzed data and cowrote the paper. Poonam Agarwal supervised the research.

\section{Data Availability Statement}

All data generated or analyzed during this study are included in this article. Further inquiries can be directed to the corresponding author.

\footnotetext{
References $\quad 1$ Beauchamp TL, Childress JF. Principles of biomedical ethics. New York, NY: Oxford University Press; 2019.

2 Williams J. Dental ethics manual. France: FDI World Dental Federation; 2007.

3 Ozar DT, Sokol DJ, Patthoff DE. Dental ethics at chairside: professional obligations and practical applications. Washington, DC: Georgetown University Press; 2018.

4 Confidentiality: NHS code of practice. London: Department of Health; 2010.
} 
5 Bourke J, Wessely S. Confidentiality. BMJ. 2008;336(7649):888-91.

6 Grady C, Jacob J, Romano C. Confidentiality: a survey in a research hospital. J Clin Ethics. 1991 Jan;2(1):25-4.

7 Erlen JA. The inadvertent breach of confidentiality. Orthop Nurs. 1998 Mar;17(2):47-50.

8 Saudi $\mathrm{MOH}$. Patient rights and responsibilities document. 2019. Available from: https:// www.moh.gov.sa/en/HealthAwareness/EducationalContent/HealthTips/Pages/001.aspx.

9 Beltran-Aroca CM, Girela-Lopez E, CollazoChao E, Montero-Pérez-Barquero $\mathrm{M}, \mathrm{Mu}$ ñoz-Villanueva MC. Confidentiality breaches in clinical practice: what happens in hospitals? BMC Med Ethics. 2016 Sep;17(1):52.
10 Ryan FS, Cedro MK, Pabari S, DavenportJones L, Noar JH. Clinicians' knowledge and practice of data protection legislation and information management. Br Dent J. 2009 Jan; 206(2):E4-1.

11 Siegler M. Confidentiality in medicine-a decrepit concept. N Engl J Med. 1982;3073(24): 1518-1521.

12 Nov 3 https://www.moh.gov.sa/en/Ministry/ Statistics/book/Pages/default.aspx.

13 Hippocrates, Adams, Francis. The genuine works of Hippocrates. New York, W. Wood and company; 1939.
14 Sankar P, Mora S, Merz JF, Jones NL. Patient perspectives of medical confidentiality: a review of the literature. J Gen Intern Med. 2003; 18(8):659-69.

15 Saudi guidelines for informed consent. 1st ed. Saudi Arabia: Saudi MOH; 2019. Available from: https://www.moh.gov.sa Accessed 2021 Nov 3.

16 Health Professions Council of South Africa. Ethical guidelines for good practice in the health care professions. HPCSA; 2016. Available from: https://www.hpcsa.co.za.

17 Behavioral violations of health service providers. Saudi Arabia: Saudi MOH; 2020. Available from: https://www.moh.gov.sa Accessed 2021 Nov 3. 